\title{
Modeling of PV Array For DC-DC Flyback Converter with Asymmetrical Output Voltage
}

\author{
J. Gowrishankar, E. Kaliappan, D. Fathema Farzana, G. V. Chidambarathanu, K. Pushpa \\ Karthick
}

\begin{abstract}
This paper manages the modeling of PV(Photovoltaic) array for Flyback converter (FBC) with Asymmetrical voltage. The Solar PV system is fed with Flyback converter on transformer in primary side. The MOSFET switch is controlled by using Maximum power tracing system with the switching frequency of $65 \mathrm{KHz}$. The Petrub and Observe algorithm is utilized in the system for controlling the switch in the converter. The Output of Flyback converter with four different asymmetrical output voltage. The input $F B C$ is $24 V$ and output $F B C$ is $6.3 V_{d c}, 12.6 V_{d c}, 26.2 V_{d c}$ and $52.4 V_{d c}$ respectively. The output capacitor is used for filter the pure DC output voltage of this system. The asymmetrical output voltage is used for Asymmetrical multilevel inverter. The system is design in $M A T L A B$ and overall system is implemented in real time system suing ARDUINO Controller, MOSFET driver circuit and ferrate core transformer.
\end{abstract}

\section{Keywords: Flyback Converter, ARDUINO}

\section{INTRODUCTION}

The Flyback DC-DC Converter is utilized very often for the maximum Switch Mode Power Supplies (SMPS) circuit for the least output power utilization,. The resultant power of the FBC type SMPS circuits might fluctuate from limited watts to an under 100 watts. The topology of FBC is significantly modest when compared to other SMPS circuits. In general, the input to the circuit is irregular and DC voltage gained by correcting the AC voltage efficiency is tracked by a modest filter capacitor. The circuit has the ability to provide single or multiple separated output voltages and to function in the above extensive period of input voltage fluctuation. In connection with energyefficiency, fly-back power delivers are low to most of the SMPS circuits. However, its modest topology and less expensive brands, it is widespread in low output power range.

In general, FBC needs a single controllable switch like, MOSFET. The common switching occurrence is in the period of $100 \mathrm{kHz}$. A dual switch topology presents the provision of much energy efficiency and low voltage pressure through the switches. However, its cost is higher

Revised Manuscript Received on 14 August, 2019.

J. Gowrishankar, department of EEE, Easwari Engineering College (Autonomous), Chennai, Tamil nadu, India. (Email: jananishankar18@gmail.com)

E. Kaliappan, department of EEE, Easwari Engineering College (Autonomous), Chennai, Tamilnadu, India.

D. FathemaFarzana, department of EEE, Easwari Engineering College (Autonomous), Chennai, Tamil nadu India. (Email: farzana.reeha@gmail.com)

G.V. Chidambarathanu, department of EEE, Easwari Engineering College (Autonomous), Chennai, Tamil Nadu, India. (Email: g.v.chidambarathanu@gmail.com)

K.PushpaKarthick, department of EEE, Easwari Engineering College (Autonomous), Chennai, Tamil Nadu, India. with marginal rise and difficulty in the circuit. The moral is restricted to the learning of FBC circuit of single switch topology [1]

\section{FLYBACK CONVERTER}

\section{A. Fly-Back Converter Basic Topology}

A modest topology of FB circuit is presented in Fig.1. An unfettered DC voltage possibly is given as input to the circuit, which results from the AC supply function. The refined and filtered input is fed into the circuit. Usually, the flow in DC voltage wave-form has a lower frequency. The complete flow voltage waveform reiterates to twice the $\mathrm{AC}$ mains frequency. The input voltage, despite being unfettered, a constant magnitude can be taken into account for slightly advanced frequency cycle, as the SMPS circuit is functioning at considerably advanced frequency (in the range of $100 \mathrm{kHz}$ ).In order to sustain with the required output voltage, a high-speed switching device (S), like a MOSFET is utilized with the high-speed active control throughout the switch duty ratio.

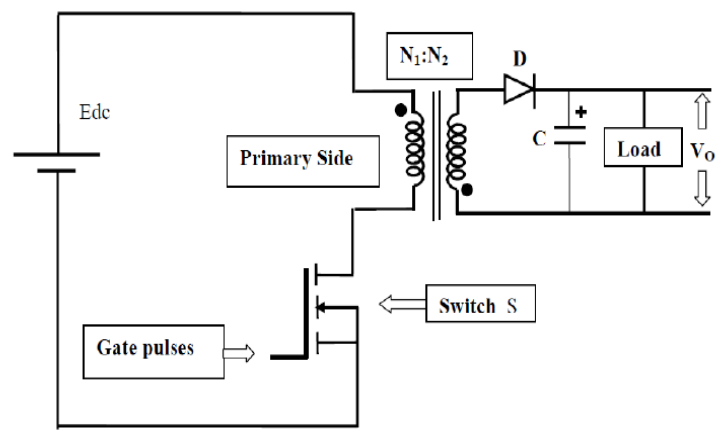

Fig 1: Fly Back Converter

As shown in a Fig. 1, the transformer is utilized for voltage fluctuations and also for improved coordination between input and output voltages and the desired current needs. Secondary windings (SW) and Primary windings (PW) of the transformer are curled to devise best coupling connected by practically identical magnetic fluctuations. In the following area that the SW AND PW of the Fly-Back Transformer (FBT) are shown as no transmitting the current concurrently. This FBT functions from a standard transformer. Primary and secondary windings show that the unique windings accomplish concurrently in a way that the ampere goes off primary winding as almost is stabilized by the conflicting

ampere-goes off the secondary winding in a standard 
trans-former which is with fewer loads. A minimal change in ampere-turns is needed for the creation of fluctuations in the non-standard principle. As the accomplishment of SW AND PW of the FBT is never concurrent, both are similar in a way two magnetically coupled inductors. Based on this reference, its appropriate to name the FBT as a inductortransformer. The magnetic circuit design of a FBT is prepared in the same way for an inductor. The study focuses on the design of inductor-transformer. The resultant part of the FBT that contains refined voltage and categorized, is standardized while comparing with the rest of SMPS circuits. [2]. As referred in the circuit Fig. 1, the voltage of secondary winding is refined and categorized, just by employing diode and a capacitor. SMPS output voltage is the voltage through the filter capacitor.[3]

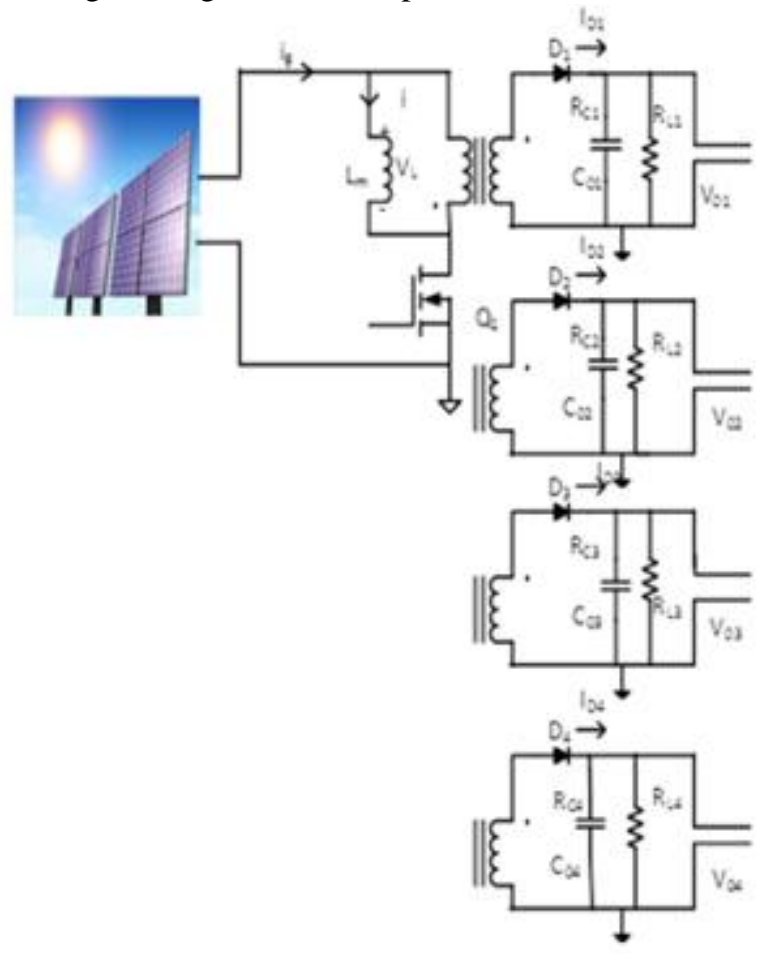

Fig 2: Fly back converter-based MPPT for solar PV system

\section{FLYBACK TRANSFORMER DESIGN}

- $\quad$ DC input voltage from solar panel, $\mathrm{V}_{\text {in }}=48$ volt

- $\quad$ Expected transformer output voltages,

$\mathrm{V}_{\text {out }}=6 \mathrm{~V}, 12 \mathrm{~V}, 24 \mathrm{~V}$ and $48 \mathrm{~V}$

- Calculation turns ratio in transformer is

$N=\frac{V_{\text {in }}}{V_{\text {out }}}=\frac{N_{\text {pri }}}{N_{\text {sec }}}$

Where, $\mathrm{N}_{\mathrm{sc}}$ - number of secondary turns and $\mathrm{N}_{\text {pri }}$ - number of primary turns

The recipe for figuring the quantity of required primary turns is:

$$
N_{\text {pri }}=\frac{\left(V_{\text {in (normal })} * 10^{8}\right.}{\left(4 * f * B_{\text {max }} * A_{c)}\right)}
$$

For figuring the required number of primary turns utilizing the recipe, the parameters or factors that should be considered are:

- $\quad \mathrm{V}_{\text {in(nom) }}$ Input Voltage Nominal. Well take this as $48 \mathrm{~V}$. So, $\mathrm{V}_{\text {in(nom) }}=48 \mathrm{~V}$.
- $\quad \mathrm{f}_{\mathrm{sw}}$ The operating switching frequency in Hertz. $\mathrm{f}_{\mathrm{sw}}$ $=65000 \mathrm{~Hz}$, considering the suitable frequency.

- $\quad \mathrm{B}_{\max }$ Maximum flux density in Gauss. If the use of Tesla or milli Tesla ( $\mathrm{T}$ or $\mathrm{mT}$ ) for transition thickness, is the training $1 \mathrm{~T}=104$ Gauss. $\mathrm{B}_{\max }$ genuine relies upon the plan and the transformer centers utilized. In the investigate plans, $\mathrm{B}_{\max }$ is taken to be in the range $1300 \mathrm{G}$ to $2000 \mathrm{G}$.

- $\quad$ This will be adequate for most transformer centers. In this illustration, immersion in might be made with $1500 \mathrm{G}$. So $\mathrm{B}_{\max }=1500$. A high $\mathrm{B}_{\max }$ will cause the transformer. Too low a $\mathrm{B}_{\max }$ will mean underutilizing of the center.

- $\quad \mathrm{A}_{\mathrm{c}}$ Powerful Cross-Sectional Area in $\mathrm{cm}^{2}$. This data from the datasheets of the ferrite centers. Air conditioning is alluded to as Ae can be acquired. For ETD39, the viable cross-sectional territory given in the data sheet the compelling cross sectional zone (in the determination sheet, alluded to as $A_{e}$ yet as said before it is same as $A_{c}$ ) given as $125 \mathrm{~mm}^{2}$ are equivalent to $1.25 \mathrm{~cm}^{2}$. In this way $A_{c}=1.25$ for ETD39.[14]

The $\mathrm{N}_{\text {pri }}$ is required parameter for calculation of all values, $\mathrm{N}_{\text {pri }}$ is the number of required primary turns obtained.

- $\mathrm{V}_{\text {in(normal) }}=48 \mathrm{~V}$

- $\mathrm{f} \quad=65 \mathrm{KHz}$

- $\mathrm{B}_{\max }=1500$

$\mathrm{A}_{\mathrm{c}} \quad=1.25 \mathrm{~cm}^{2}$

$N_{\text {pri }}=\frac{\left(48 * 10^{8}\right)}{(4 * 65000 * 1500 * 1.25)}$

$N_{\text {pri }}=10.6667$

Number of windings is not selected as fractional. So take $N_{\text {pri }}=11$ turns

So, the selected number of primary turns is

$N_{\text {pri }}=11+11$ turns

Due to construction difficulties, even number of turns only selected. So

$N_{\text {pri }}=12+12=24$ turns

Secondary side turns Calculation:

$$
\text { Turns ratio }=\frac{\text { Secondary side turns }}{\text { Primary side turns }}
$$

Secondary side turns $=$

Turns ratio $*$ Primary side turns

Turns ratio for $6 \mathrm{~V}$ is

Turns ratio $\left(\mathrm{K}_{1}\right)=6 / 48=0.125$

Turns ratio for $12 \mathrm{~V} \mathrm{i}$

Turns ratio $\left(\mathrm{K}_{1}\right)=12 / 48=0.25$

Turns ratio for $24 \mathrm{~V}$ is

Turns ratio $\left(\mathrm{K}_{1}\right)=24 / 48=0.5$

Turns ratio for $45 \mathrm{~V}$ is

Turns ratio $\left(\mathrm{K}_{1}\right)=48 / 48=1$

Number of secondary side turns is

$\mathrm{N}_{1}=0.125 * 24=3$ Turns

$\mathrm{N}_{2}=0.25^{*} 24=6$ Turns

$\mathrm{N}_{1}=0.5 * 24=12$ Turns

$\mathrm{N}_{1}=1 * 24=24$ Turns

- $\quad$ Primary voltage DC: $48 \mathrm{~V}, 2 \mathrm{~A}$

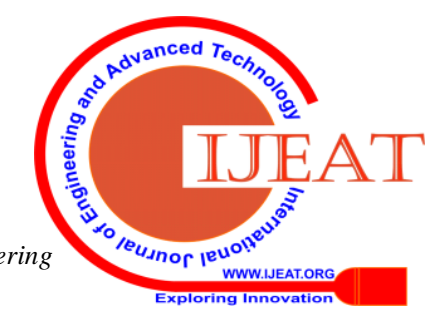


- $\quad$ Number of primary turns: 24

Table.1 Ferraite core transformer- No of secondary turns and Secondary voltage

\begin{tabular}{|cc|c|c|c|c|}
\hline $\begin{array}{c}\text { Secondary } \\
\text { Voltage }\end{array}$ & $\begin{array}{c}6 \mathrm{~V}, 5 \\
00 \mathrm{~mA}\end{array}$ & $\begin{array}{c}12 \mathrm{~V}, 5 \\
00 \mathrm{~mA}\end{array}$ & $\begin{array}{c}24 \mathrm{~V}, 5 \\
00 \mathrm{~mA}\end{array}$ & $\begin{array}{c}48 \mathrm{~V}, 50 \\
0 \mathrm{~mA}\end{array}$ \\
\hline $\begin{array}{c}\text { secondary side } \\
\text { (No. of turns) }\end{array}$ & 3 & 6 & 12 & 24 \\
\hline
\end{tabular}

\section{DC-DC CONVERTER DIODE AND} CAPACITOR VALUE

- $\quad$ Diode bridge rectifier: W10

- Capacitor for 1st output of transformer: 100f,16V

- $\quad$ Capacitor for 2nd output of transformer: 47f,63V

- Capacitor for 3rdoutput of transformer: 47f,63V

- Capacitor for 4th output of transformer: 100f,160V

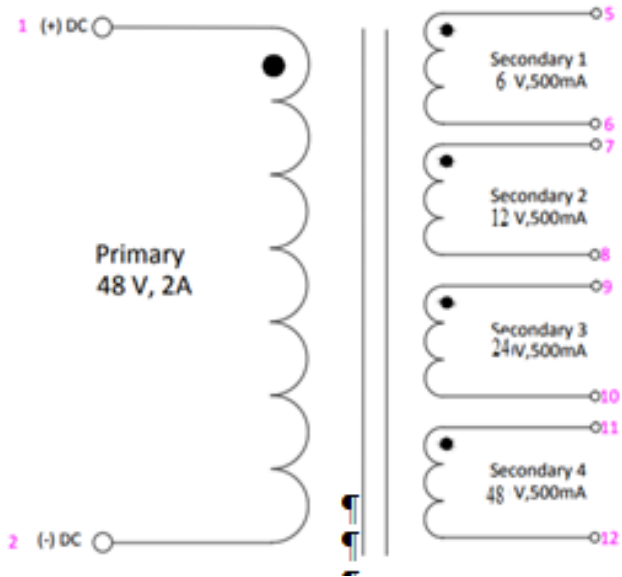

Fig 3; Transformer Input and output Voltage

\section{SPECIFICATION OF DC-DC FLYBACK CONVERTER\& RESULTS}

The MATLAB software is being used to implement input and output voltage ad cur-rent waveforms in existing multilevel inverter circuits. In this operating mode we are targeting for a significant perfection by evolving 31 levels of output voltages.[11]

Table 2 DCDC Flyback Converter Parameters Details

\begin{tabular}{|c|c|c|}
\hline S.no & Parameters & Value \\
\hline 1. & Input Voltage $\left(\mathrm{V}_{\mathrm{dc} 1}\right)$ & $48 \mathrm{~V}$ \\
\hline 2. & Output Voltage $\left(\mathrm{V}_{\mathrm{dc} 2}\right)$ & $6.6 \mathrm{~V}$ \\
\hline 3. & Output Voltage $\left(\mathrm{V}_{\mathrm{dc} 3}\right)$ & $13.2 \mathrm{~V}$ \\
\hline 4 & Output Voltage $\left(\mathrm{V}_{\mathrm{dc} 4}\right)$ & $26.4 \mathrm{~V}$ \\
\hline 5 & Output Voltage $\left(\mathrm{V}_{\mathrm{dc} 5}\right)$ & $52.8 \mathrm{~V}$ \\
\hline 6 & Switching Frequency $\left(\mathrm{f}_{\mathrm{sw}}\right)$ & $65 \mathrm{KHz}$ \\
\hline
\end{tabular}

Above given values are the outputs from the converter of the input given to the multilevel inverter.

\section{HARDWARE IMPLEMENTATION OF ASYMMETRICAL OUTPUT VOLTAGE WITH PV SYSTEM}

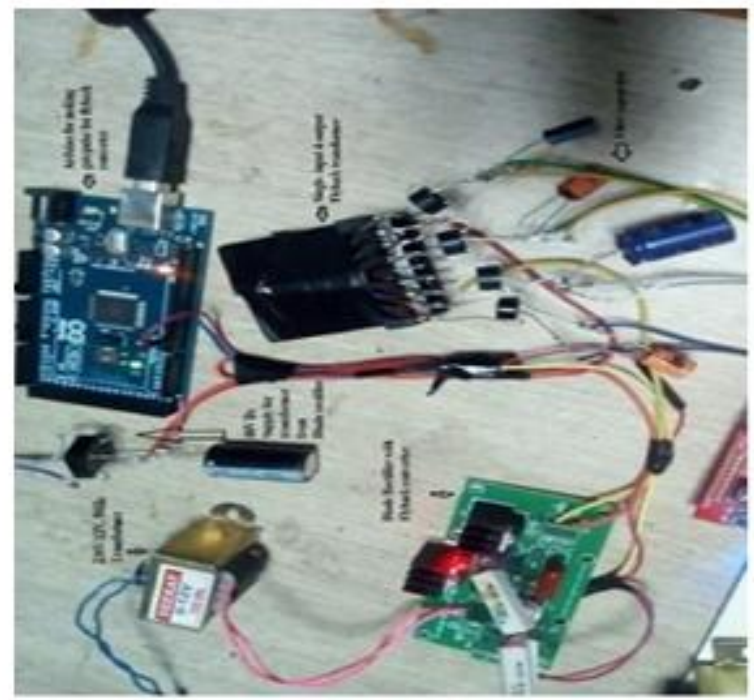

Fig 4 Hardware circuit for Flyback Converter

The above Fig. $\underline{4}$ shows the circuit of Hardware circuit for flyback converter. The FBC which is regularly utilized keep up steady DC voltage for load., Here flyback converter is used for regulating DC voltage and generate 4-different kinds of DC voltage as output. The flyback transformer with multi-tapping is shown in Fig. $\underline{7}$ These four different voltages of ratio 1:2:4:8 is used as supply voltage of inverter. The switch present in flyback converter is MOSFET-IRF840 and gate pulse for this switch is generated by ATMEGA328. The switching frequency of this switch is 65KHZ.Fig. 8shows the supply voltage for a flyback converter. The $48 \mathrm{~V}_{\mathrm{dc}}$ supply is obtained from solar PV, which is given to the input for FBC.[10]

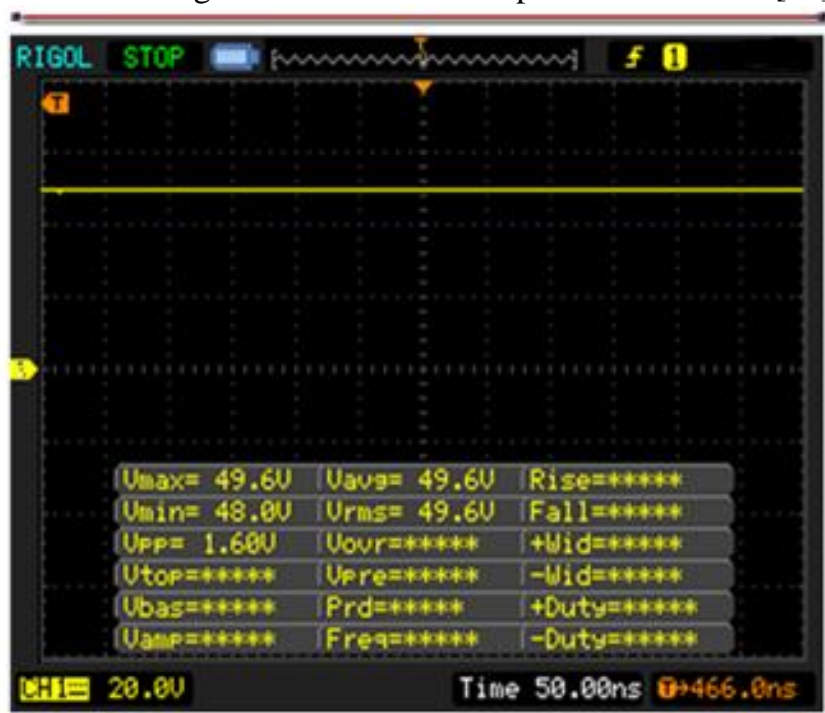

Fig 5 Output Voltage for Solar System

Fig 6 shows the Gate pulse for DC-DC flyback converter (65KHZ).

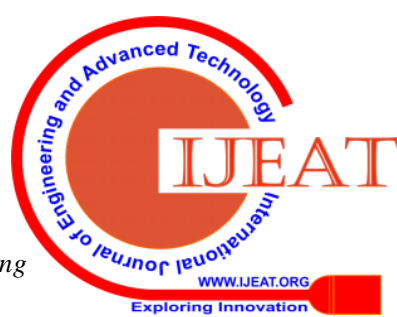




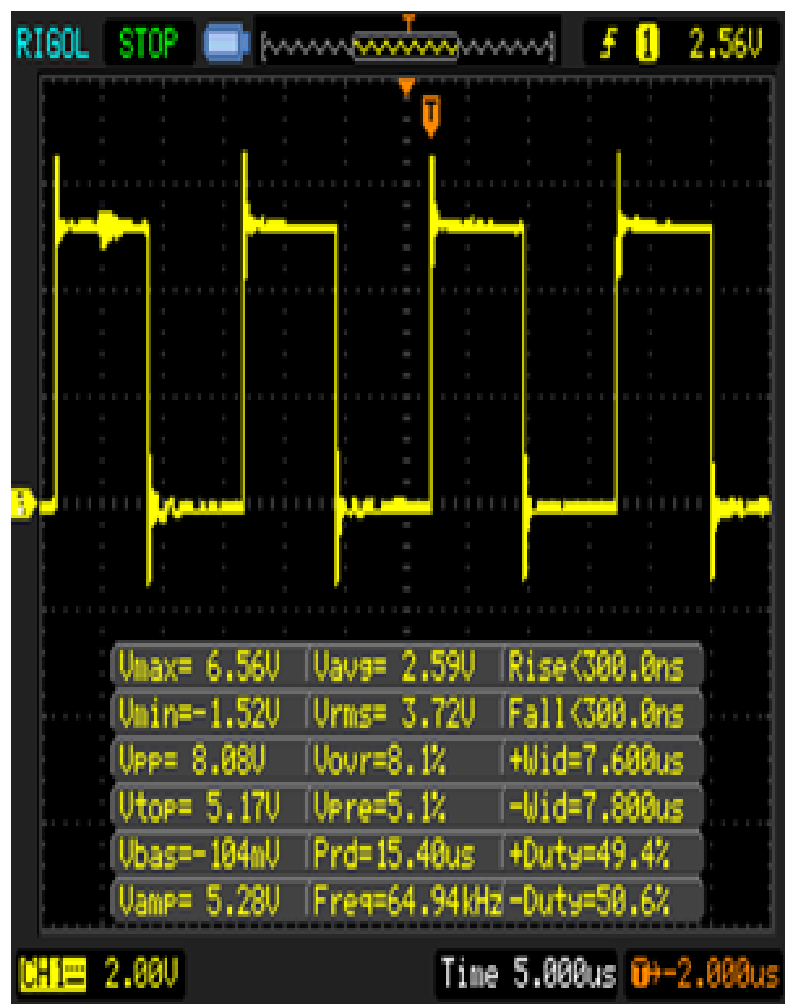

Fig6: Switching frequency for DC-DC flyback converter

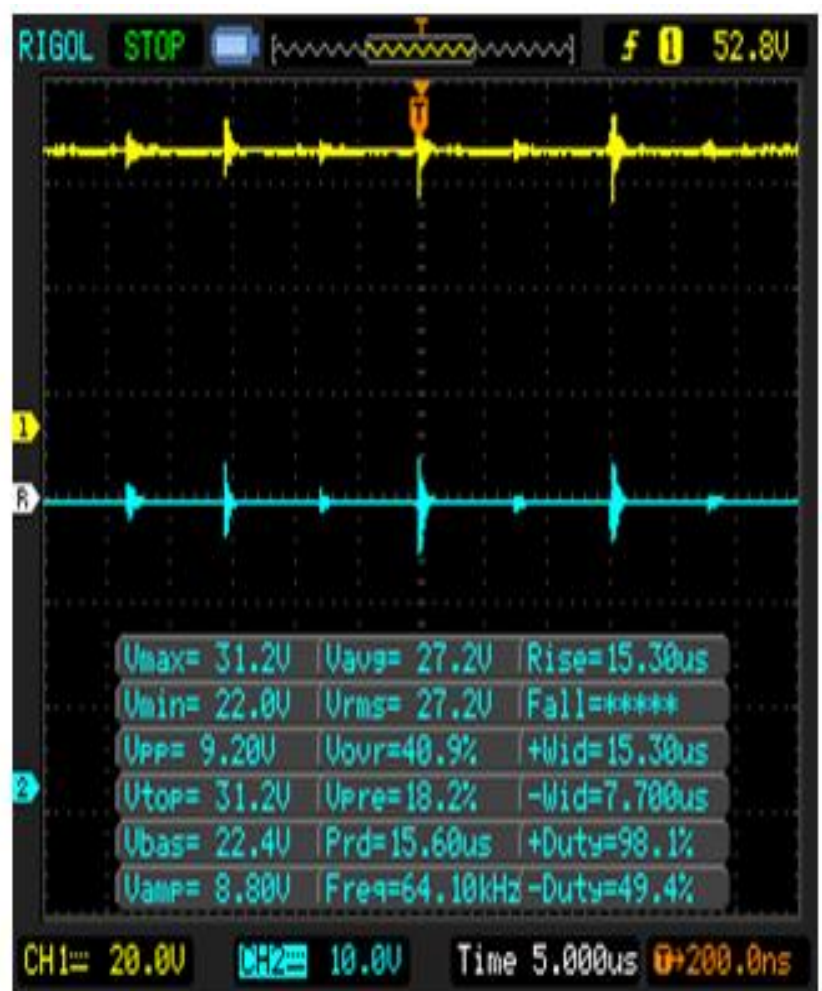

Fig 7; $V_{d c 1}$ and $V_{d c 2}$ tapping Output voltage from fly back transformer

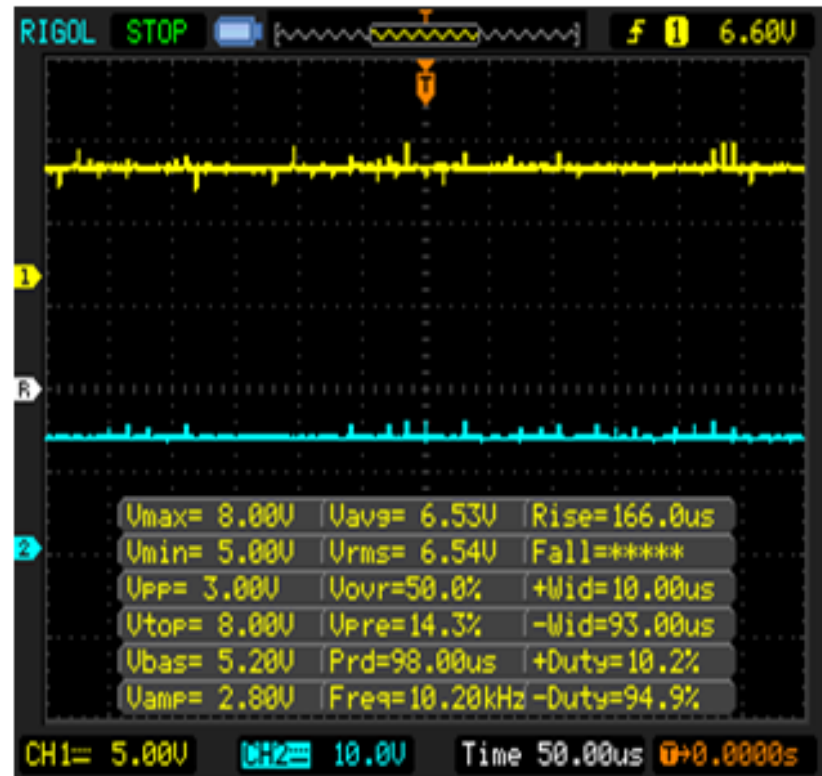

Fig $8 V_{d c 3}$ and $V_{d c 4}$ tapping Output voltage from fly back transformer

\section{CONCLUSION}

This paper is deals with single input and four asymmetrical output FBC. The input FBC voltage of the converter is $48 \mathrm{~V}$, the switching frequency of the $\mathrm{FBC}$ is $65 \mathrm{Khz}$, the Maximum Flux density $\left(\mathrm{B}_{\max }\right)=1500$ and Area of the core $\left(\mathrm{A}_{\mathrm{c}}\right)=1.25 \mathrm{~cm}^{2}$. The Number of primary turns is 24 turns, on the secondary side of the converters the number of turns are 3,6,12 and 24.The overall system is analyzed in real time system by using ATMEGA 2560 controller. The output PWM signal of controller is $3.3 \mathrm{~V}$. To boost the voltage from $3.3 \mathrm{v}$ to $12 \mathrm{~V}$ the MOSFET driver TLP350 circuit is used. The capacitor filter is used for converter to reduce the fluctuation voltage. The capacitor value for $\mathrm{C}_{1}=100 \mu \mathrm{f}, 16 \mathrm{~V}, \mathrm{C}_{2}=47 \mu \mathrm{f}, 63 \mathrm{~V}, \mathrm{C}_{3}=47 \mu \mathrm{f}, 63 \mathrm{~V}$ and $\mathrm{C}_{4}=100 \mu \mathrm{f}$. The output voltage of the converter is 6.3 $\mathrm{Vdc}, 12.6 \mathrm{Vdc}, 25.2 \mathrm{Vdc}$ and $52.4 \mathrm{Vdc}$ respectively.

\section{REFERENCES}

1. Branker, K., Pathak, M. and Pearce, J. M. (2011), 'A review of solar photovoltaic lev-elized cost of electricity', Renewable and sustainable energy reviews 15(9), 4470-4482.

2. Esram, T. and Chapman, P. L. (2007), 'Comparison of photovoltaic array maximum power point tracking techniques', IEEE Transactions on energy conversion 22(2), 439- 449

3. Kazimierczuk, M. K. (2008), 'Flyback PWM DC-DC converter', Pulse-width Modulated DC-DC Power Converters pp. 189-237

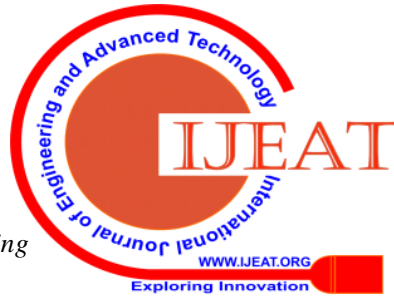

